\title{
Learning from Job: A Rare Genetic Disease and Lessons of Biblical Proportions
}

\author{
Joshua D. Milner, M.D.* \\ Chief, Laboratory of Allergic Diseases, National Institute of Allergy and Infectious Diseases, National \\ Institutes of Health, Bethesda, Maryland, USA
}

\begin{abstract}
Dominant negative mutations in STAT3, a critical signaling molecule and transcription factor in multiple organ systems, lead to a rare monogenic disease called the STAT3 loss-of-function, autosomal dominant hyper-IgE syndrome (STAT3LOF AD-HIES). The original name for this syndrome, Job's syndrome, was derived from the observation that patients had a propensity to develop skin boils, reminiscent of the affliction cast upon the biblical Job. Many fascinating observations have been made regarding the pathogenesis of the disease and the role STAT3 plays in human health and disease. Additionally, quite a few phenotypic descriptions from the Book of Job are similar to those seen in patients with STAT3LOF ADHIES, beyond just the boils. This complex multisystem genetic disorder is a challenge clinically and scientifically, but it also brings into question how we approach genetic syndromes beyond just the technical aspects of research and treatment.
\end{abstract}

KEY WORDS: Hyper-IgE, infection, monogenic disease

\begin{abstract}
Abbreviations: STAT3LOF AD-HIES, STAT3 loss-of-function, autosomal dominant hyper-IgE syndrome.
Citation: Milner JD. Learning from Job: A Rare Genetic Disease and Lessons of Biblical Proportions. Rambam Maimonides Med J 2018;9 (1):eooo6. Review. doi:10.5041/RMMJ.10326

Copyright \& Disclaimer Statement: This paper was written as part of the author's official duties as a NIH employee and is a Work of the United States Government. As such permission is granted worldwide to reproduce, prepare derivative works, distribute copies to the public, and perform publicly and display publicly the work, and to permit others to do so. The views expressed in this article are those of the author and do not necessarily represent the views of the National Institutes of Health or the United States Department of Health and Human Services.
\end{abstract}

Acknowledgements: This work was supported by the Intramural Research Program of the NIAID, NIH. English translations are based on the English text in sefaria.org and the Jewish Publication Society 1917 Bible translation. The author thanks Aliza Sperling and Bayla Jacobson for critical readings of the manuscript.

Conflict of interest: No potential conflict of interest relevant to this article was reported.

* E-mail: jdmilner@niaid.nih.gov 


\section{INTRODUCTION}

Studying rare genetic syndromes can provide invaluable insight into fundamental pathways in health and disease, beyond the benefit to the rare patient affected by such disorders. In years past, such novel syndromes tended to be named either to correspond to a specific symptom commonly associated with it (e.g. familial Mediterranean fever) or after the name of the physician(s) involved in the initial description of the disorder (e.g. Wiskott-Aldrich syndrome). One unique outlier not initially named by any of these criteria is Job's syndrome. In 1966, Ralph Wedgwood and colleagues in Seattle encountered two sisters with a significant, long-standing history of skin boils, which, interestingly, were not associated with the signs of inflammation expected from such infections and were hence described as "cold" abscesses. The decision was made to call the disorder Job's syndrome, recalling the boils afflicted upon the biblical character Job as a test that emerged from an exchange between G-d and Satan. (2:7 So Satan went forth from the presence of the $L O R D$, and smote Job with sore boils from the sole of his foot even unto his crown.) ${ }^{1}$

This disorder is extremely rare-there may be fewer than 1,00o people in the world affected-but it has been studied extensively ever since because of the complicated symptoms these patients can develop, and for the insight the underlying cause provides into the human immune system, musculoskeletal and circulatory systems, and more.

Since the initial naming, two substantial findings over the years have provided additional names. The first was that IgE-the antibody most tightly associated with allergic reactivity-is markedly elevated in these patients, ${ }^{2}$ prompting the name "the hyper-IgE syndrome" or the "autosomal dominant hyper-IgE syndrome." Interestingly, in part because the observation of high IgE was made by legendary pediatric immunologist Rebecca Buckley, for some period of time the disease bore her name, "Buckley syndrome." Subsequently, however, multiple syndromes with presentations and inheritance patterns distinct from Job's syndrome have been identified which lead to such IgE elevations, including even another autosomal dominant one (CARD11 mutations 3 ), leading to the need for a more precise term. The second was the discovery that dominant negative mutations in STAT3, a critical transcription factor for numerous cellular signaling pathways, underlie the disorder.4,5 Subsequently gain-of-function muta- tions in STAT3 were identified in patients with autoimmunity and lymphoproliferation, ${ }^{6-8}$ necessitating the clarifying title "STAT3 loss-of-function" (STAT 3 LOF). With its negative connotation of affliction with a disorder of biblical proportions, the name Job's syndrome is now less commonly used; the more descriptive STAT3LOF AD-HIES (STAT3 loss-of-function, autosomal dominant hyper-IgE syndrome) better captures the disease. It is noteworthy that the progression of terms-from a malady of biblical dimension, to a description of a remarkably abnormal clinical finding not necessarily central to the disease, to the genetic root cause of the disorder-mirrors in many ways how we have evolved in our understanding of such diseases in general.

The title Job's syndrome was perhaps more prescient than initially recognized. Beyond the boils and infections which were noted initially, many of the symptoms with which the patients present can be found-without too much stretching of the imagination-in the text of the Book of Job, either from Job's descriptions of his fate or in the descriptions by those who came to console him.

\section{THE PHENOTYPE OF STAT3LOF AD-HIES AND PATHOPHYSIOLOGIC MECHANISMS}

Patients with STAT3LOF mutations develop chronic mucocutaneous candidiasis (CMC) throughout their lives and can get skin rashes which resemble atopic dermatitis from birth, differing from classic atopic dermatitis. (2:4 And Satan answered the LORD, and said: "Skin for skin, yea, all that a man hath will he give for his life."/7:5 My skin is broken and festering.) Eosinophilic esophagitis-associated with difficulty swallowing, impacted food (20:15 The riches he swallows he vomits/20:18 He will give back the goods unswallowed; The value of the riches undigested), and resulting in refusal to eat at times (6:7 I refuse to touch them; They are like food when I am sick)-has been observed as well. ${ }^{9}$

The non-immunologic symptoms in these patients include joint hypermobility (31:22 May my arm drop off my shoulder), failure of childhood teeth to fall out (13:14 How long! I will take my flesh in my teeth/19:20 I escape with the skin of my teeth), easily fractured bones (2:5 But put forth Thy hand now, and touch his bone and his flesh, surely he will blaspheme Thee to Thy face./31:22 My forearm break off at the elbow) possibly due to increased bone resorptive activity (30:17 By night my bones feel gnawed), 5 scoliosis, characteristic 
facies including a broad nasal bridge and asymmetry, and aneurysm formation, primarily in the coronary arteries (17:11 My days are done, my tendons severed, The strings of my heart). 9

Perhaps the manifestation with the greatest morbidity is lung disease, principally caused by Staphylococcus aureus infection, which can lead to cavitating lung cysts (pneumatoceles) and bronchiectasis (9:18 He does not let me catch my breath). Other infections patients can encounter include $\mathrm{CMC}$, recurrent pneumococcal and Gram-negative respiratory tract infections, and invasive fungal diseases. 9

Primary viral infection does not appear to be a significant issue, but herpesvirus reactivation in the form of Varicella Zoster Virus and chronic EpsteinBarr virus viremia have been observed. The precise mechanisms for infections continue to be elucidated. The candidiasis appears to be due to the lack of a specific type of cytokine needed for anti-candidal responses, IL-17, ${ }^{10-12}$ and some of the bacterial infections may be explained by B-cell defects in maturation and memory development, which in some patients is prevented by intravenous immune globulin. ${ }^{13,14}$ In general, it appears that patients have difficulty with maintaining the long-term cellular "memory" needed to normally keep certain infections at bay, thereby allowing such infections to persist or recur abnormally.13,15

\section{STAT3LOF AD-HIES AS A PARADIGM FOR ALTERING THE BALANCE OF PROTECTION FROM INFECTION AND SUSCEPTIBILITY TO INFLAMMATION}

On another level, some of the deeper messages in the biblical text bear some similarities to this unique disorder as well, as will be outlined below. Of course, no one would really try to claim that Job actually had Job's syndrome. (Of note, a colleague of mine once circulated a remarkably realistic-appearing article from a prominent journal claiming to have found bones in an ossuary in Ashkelon with Job's name on it that tested positive for a known mutation in STAT3; the text was sent on April 1-or April Fool's Day.)

The adult onset of Job's symptoms (as opposed to infancy, which also would have been fatal prior to intravenous immune globulin and antibiotics), and the lack of any noted family history of this dominant disorder makes this congenital disease a highly un- likely cause (the tragic death of his children, again after infancy, is due to attacking groups and to a mysterious "wind"). Scholars in the medical literature have proposed everything from kidney disease, ${ }^{16}$ to primary dermatologic disorders, ${ }^{17,18}$ to poisoning, ${ }^{19}$ to psychiatric disorders, ${ }^{20,21}$ and have taken to psychoanalyzing Job as well. ${ }^{22-25}$ Nonetheless, it is valuable to ponder ancient encounters with disease and affliction, and contrast them to the modern ways that we understand, perceive, and deal with genetic diseases. Like the affliction of Job, these diseases are well beyond the control of those affected and lead to tremendous challenges and suffering. Scholars have focused on the "doctor-patient relationship," as it were, between Job and the various other characters in the book, and on the process of grieving and consolation in general, ${ }^{26-29}$ and today, in an era when the underlying genetic cause of biological differences and/or disease can frequently be identified (sometimes even before a symptom appears), an oft-ignored issue arises: Whether or not a cure is found, how is the affected individual and his/her caregivers to understand and cope with such a rare disease that is fated from birth? Even when the precise genetic cause is identified, does it provide any more solace?

What brings Job the most solace is a lecture from G-d at the very end of the book. It is fundamentally about how humans and other living beings cannot possibly know or control all the various differences or "mistakes" that are made that lead to good and bad outcomes in nature. In one instance G-d points out (Job 39) regarding the ostrich that "14 She leaves her eggs on the ground, Letting them warm in the dirt, 15 Forgetting they may be crushed underfoot, Or trampled by a wild beast." As the nineteenth-century biblical commentator Malbim points out, this is contrasted to the stork that flies high but lays few eggs which must be guarded more carefully, "18 Else she would soar on high, Scoffing at the horse and its rider."

One could interpret this point as G-d trying to explain to Job that in addition to the basic lack of insight into nature, an insight that he will never really have, there will always be a tradeoff between advantages and disadvantages-soaring freedom and risk for disaster-which are exceedingly difficult to understand, and therefore the particular set point of risk for any individual will always come into question. STAT3LOF AD-HIES is not the only rare genetic disease with such tradeoffs (the causal mutation in Sickle cell anemia protects the unaffected 
carriers from malaria, and theories have been proposed that unaffected carriers of the gene causing Tay-Sachs might be more intelligent), but it is a good example of one, and certainly makes anyone affected wonder: "why me?"

Amongst the tradeoffs noted in STAT3LOF ADHIES, a major one is the lack of damaging inflammation at the cost of increased infection. The abscesses seen in these patients fail to express cardinal signs of inflammation such as swelling (tumor), heat (calor), redness (rubor), and pain (dolor)-a potential departure from the biblical Job ("2:8 and he sat among the ashes ...", which is interpreted by some to mean not just mourning but the need to cool off his "hot" wounds). In addition, while the patients fracture bones easily, they tend to not realize the extent of their injury. The pneumonias that occur are not associated with the level of discomfort one might expect until they are quite severe, and in fact are sometimes only diagnosed with grossly abnormal CT scans-necessitating careful imaging studies even in the absence of illness. It is also interesting that, despite having such high levels of allergy-associated IgE, patients are relatively protected from severe allergic disease and anaphylaxis. The mechanism appears to be a requirement for normal STAT3 function in mast cell degranulation and endothelial responses to histamine, and in fact in vivo treatment of mice with STAT3 inhibitors prevents anaphylaxis..$^{30,31}$ Furthermore, while again diverging from the biblical Job (20:14 His food in his bowels turns into asps' venom within him) the lack of food allergy observed in this rare disease associated with the overproduction of an antibody associated with allergy actually led to the identification of a potential therapeutic targetinhibition of STAT3-to treat severe allergy in the general population.

Further, patients with STAT3 deficiency might have been predicted to have colitis, since patients with loss of the IL-10 receptor-which signals through STAT3-have severe early-onset inflammatory bowel disease (IBD). ${ }^{32}$ However, unlike the biblical Job (30:27 My bowels are in turmoil without respite), they do not, potentially due to the lack of Th17 cells. ${ }^{10}$ Study of STAT3LOF AD-HIES patients first demonstrated the consequence of a lack of these cells, namely CMC, but their absence may also explain why IBD and perhaps other types of autoimmunity are absent. Indeed, blocking IL-17 is an effective treatment in a variety of inflammatory and autoimmune conditions. 33 Despite the heart disease caused by aneurysm, the coronary arteries in these patients are relatively (though not completely) protected from the plaque and atherosclerosis that might be expected. ${ }^{34-36}$ One also wonders if joint hypermobility, which on the one hand can be associated with chronic pain and arthritis, might nonetheless confer an advantage to individuals in certain scenarios.

It is indeed quite possible that some of these paradoxical protections-from certain types of pain, inflammation, atherosclerosis, allergy, and autoimmune disease-might well confer an advantage, as opposed to reflecting further disease. They represent a different set point for the tradeoff between excessive inflammation and excessive infection. While the disease can be quite severe in many patients, early management can, in a substantial subset of these patients, prevent many of the worst symptoms. Finally, once past their adolescent years, patients who have been able to manage their infections earlier in life tend to see a reduction in infection, and even in IgE levels. There can be patients who are "restored" (42:10 And the LORD changed the fortune of Job, when he prayed for his friends; and the LORD gave Job twice as much as he had before) as it were, but not without the scars of their ordeal, and not without future suffering or risk of disease.

\section{APPROACHING GENETIC SYNDROMES: DO WE ADEQUATELY ADDRESS THE AFFECTED PERSON AND THEIR CONCERNS IN THEIR ENTIRETY?}

In proving G-d correct over Satan, Job curses the day he was born (perhaps when a congenital issue would first manifest?) but does not curse G-d. Nonetheless, his "friends" who come to console him do anything but. Much of their rebuke could be summarized as: "Buck up, who are you to complain? You probably deserved it because of some sin, and repentance will be the cure." In truth there could be no consolation for his loss, only a restoration of faith and property, which happens after Job comes to terms with his relationship to the divine (and in a universalist setting, perhaps that which is beyond his reach or control) and to others (his visiting friends with whom he has a reconciliation).

It may never be fully understood what about G-d's lecture helped Job to get there. Such insight will never fully console or restore anyone, but at least it may help to reframe the issue for all of us- 
from patients to impacted loved ones, to health-care providers-in an era of unprecedented technological advances which get at the genetic and biological causes of myriad afflictions, often a long time prior to any practical treatment based on the finding.

In an essay about the dimensions of palliative care in suffering patients, Theodore Fleischer uses the Book of Job as a model for dealing with severe illness and suffering in the face of modern technological advances which, in his view, fail to address a dimension important in many of those with diseases: "Why do I have this?" 27 While his essay was about end-of-life palliative care, the analysis could well be applied to the complexities of being born with a rare multisystem congenital disorder. Indeed, the research into how to try and cure the suffering is critical. But faith in a cure, or, believe it or not, the cure itself is probably not enough for many. Noting that the visitors to Job repeatedly harped on his complaining and cursing of the day he was born, and told him that sin-which Job felt he did not commit-was the reason he was afflicted, Fleischer writes:

Solutions that utilize only techniques to manage pain ignore the patients' need to interpret their experiences of suffering. Like the religious solution [repentance] rejected by Job ... this topical remedy falls short of providing an answer to the patients' search for a stance that allows them to cope with the depth of their suffering. Palliative care cannot substitute for meaning. ${ }^{27}$

And later he notes:

The story of Job illuminates dimensions of suffering that are as relevant today as they were in biblical times. All who suffer need to interpret their suffering. Job rejected a solution that failed to acknowledge the depth of his disorientation and the abyss that separated him from God and his fellow humans. Instead, he found a solution in renewed covenantal relationships with God and the human community. Only then could Job reclaim his suffering. ${ }^{27}$

Regarding patients themselves who struggle with these issues:

When they refused to be distracted by technological solutions and instead sought to understand the role of suffering in their lives, they were finally able to truly express their autonomy. ${ }^{27}$

As a final note, a word to the wise from Job himself for those, like his visitors, who try too hard to approach this problem without truly understanding all the dimensions of suffering an affected person might have: "13:4 But you invent lies; All of you are doctors for idols." Understanding the technical dimensions of genetic diseases in order to improve the physical health of affected patients is of course critical, and in this era such diseases will be genetically solved at an extraordinary rate. However, care must be taken not to ignore the more fundamental questions of what it means to be born with a "mutation," and to understand that the affected individual has been the made the subject of a different set of tradeoffs of gain and loss of function of different pathways inherent in any biological system in balance that sets them apart and leaves them wondering why. Caregivers should have that in mind when approaching such populations.

\section{REFERENCES}

1. Davis SD, Schaller J, Wedgwood RJ. Job's syndrome. Recurrent, "cold", staphylococcal abscesses. Lancet 1966;1:1013-15. Crossref

2. Buckley RH, Wray BB, Belmaker EZ. Extreme hyperimmunoglobulinemia $\mathrm{E}$ and undue susceptibility to infection. Pediatrics 1972;49:59-70.

3. Ma CA, Stinson JR, Zhang Y, et al. Germline hypomorphic CARD11 mutations in severe atopic disease. Nat Genet 2017;49:1192-201. $\underline{\text { Crossref }}$

4. Holland SM, DeLeo FR, Elloumi HZ, et al. STAT3 mutations in the hyper-IgE syndrome. N Engl J Med 2007;357:1608-19. Crossref

5. Minegishi Y, Saito M, Tsuchiya S, et al. Dominantnegative mutations in the DNA-binding domain of STAT3 cause hyper-IgE syndrome. Nature 2007;448: 1058-62. $\underline{\text { Crossref }}$

6. Flanagan SE, Haapaniemi E, Russell MA, et al. Activating germline mutations in STAT3 cause earlyonset multi-organ autoimmune disease. Nat Genet 2014;46:812-14. Crossref

7. Haapaniemi EM, Kaustio M, Rajala HL, et al. Autoimmunity, hypogammaglobulinemia, lymphoproliferation, and mycobacterial disease in patients with activating mutations in STAT3. Blood 2015;125:63948. $\underline{\text { Crossref }}$

8. Milner JD, Vogel TP, Forbes L, et al. Early-onset lymphoproliferation and autoimmunity caused by 
germline STAT3 gain-of-function mutations. Blood 2015;125:591-9. Crossref

9. Sowerwine KJ, Holland SM, Freeman AF. Hyper-IgE syndrome update. Ann N Y Acad Sci 2012;1250:2532. $\underline{\text { Crossref }}$

10. Milner JD, Brenchley JM, Laurence A, et al. Impaired $\mathrm{T}(\mathrm{H}) 17$ cell differentiation in subjects with autosomal dominant hyper-IgE syndrome. Nature 2008;452: 773-6. $\underline{\text { Crossref }}$

11. de Beaucoudrey L, Puel A, Filipe-Santos O, et al. Mutations in STAT3 and IL12RB1 impair the development of human IL-17-producing T cells. J Exp Med 2008;205:1543-50. $\underline{\text { Crossref }}$

12. Ma CS, Chew GY, Simpson N, et al. Deficiency of Th17 cells in hyper IgE syndrome due to mutations in STAT3. J Exp Med 2008;205:1551-7. $\underline{\text { Crossref }}$

13. Avery DT, Deenick EK, Ma CS, et al. B cell-intrinsic signaling through IL-21 receptor and STAT3 is required for establishing long-lived antibody responses in humans. J Exp Med 2010;207:155-71. Crossref

14. Meyer-Bahlburg A, Renner ED, Rylaarsdam S, et al. Heterozygous signal transducer and activator of transcription 3 mutations in hyper-IgE syndrome result in altered B-cell maturation. J Allergy Clin Immunol 2012;129:559-62, 62 e1-2.

15. Siegel AM, Heimall J, Freeman AF, et al. A critical role for $\mathrm{STAT}_{3}$ transcription factor signaling in the development and maintenance of human T cell memory. Immunity 2011;35:806-18. Crossref

16. Resende LA, Kirchner DR, Ruiz e Resende LS. Solving the conundrum of Job: a probable biblical description of chronic renal failure with neurological symptoms. Arq Neuropsiquiatr 2009;67(2B):544-7. Crossref

17. Holubar K. Dermatology in biblical perspective. An illustration from the book of Job. Am J Dermatopathol 1985;7:437-9. $\underline{\text { Crossref }}$

18. Appelboom T, Cogan E, Klastersky J. Job of the Bible: leprosy or scabies? Mt Sinai J Med 2007;74:36-9. Crossref

19. Gorman S, Kaplan DL. The affliction of Job: poisoned! J Am Acad Dermatol 1999;40:126-8.

20. Bowman RG. Some reflections on the book of Job. Psychiatr Commun 1973;14:37-42.

21. Kapusta MA, Frank S. The book of job and the modern view of depression. Ann Intern Med 1977;86: 667-72. $\underline{\text { Crossref }}$

22. Slochower H. The Book of Job: the Hebrew myth of the Chosen God, its symbolism and psychoanalytic. Int Rec Med Gen Pract Clin 1958;171:761-9.
23. Reid SA. The Book of Job. Psychoanal Rev 1973;60: 373-91.

24. Achenbaum WA, Orwoll L. Becoming wise: a psychogerontological interpretation of the Book of Job. Int $\mathrm{J}$ Aging Hum Dev 1991;32:21-39. Crossref

25. Roy A. The Book of Job: a grief and human development interpretation. J Relig Health 1991;30:149-59. Crossref

26. Renik O. The Biblical Book of Job: advice to clinicians. Psychoanal Q 1991;60:596-606.

27. Fleischer TE. Suffering reclaimed: medicine according to Job. Perspect Biol Med 1999;42:475-88. Crossref

28. Lyon DS. Before Kubler-Ross: lessons about grief from the book of Job. Obstet Gynecol 2000;96:151-2. Crossref

29. Roxberg A, Brunt D, Rask M, da Silva AB. Where can I find consolation? A theoretical analysis of the meaning of consolation as experienced by job in the Book of Job in the Hebrew Bible. J Relig Health 2013;52:114-27. $\underline{\text { Crossref }}$

30. Siegel AM, Stone KD, Cruse G, et al. Diminished allergic disease in patients with STAT3 mutations reveals a role for STAT3 signaling in mast cell degranulation. J Allergy Clin Immunol 2013;132:1388-96. Crossref

31. Hox V, O'Connell MP, Lyons JJ, et al. Diminution of signal transducer and activator of transcription 3 signaling inhibits vascular permeability and anaphylaxis. J Allergy Clin Immunol 2016;138:187-99. $\underline{\text { Crossref }}$

32. Glocker EO, Kotlarz D, Klein C, Shah N, Grimbacher B. IL-10 and IL-10 receptor defects in humans. Ann N Y Acad Sci 2011;1246:102-7. Crossref

33. Fasching P, Stradner M, Graninger W, Dejaco C, Fessler J. Therapeutic potential of targeting the Th17/Treg axis in autoimmune disorders. Molecules 2017;22(1). Crossref

34. Freeman AF, Avila EM, Shaw PA, et al. Coronary artery abnormalities in Hyper-IgE syndrome. J Clin Immunol 2011;31:338-45. Crossref

35. Chandesris MO, Azarine A, Ong KT, et al. Frequent and widespread vascular abnormalities in human signal transducer and activator of transcription 3 deficiency. Circ Cardiovasc Genet 2012;5:25-34. Crossref

36. Abd-Elmoniem KZ, Ramos N, Yazdani SK, et al. Coronary atherosclerosis and dilation in hyper IgE syndrome patients: depiction by magnetic resonance vessel wall imaging and pathological correlation. Atherosclerosis 2017;258:20-5. $\underline{\text { Crossref }}$ 